\title{
CONTROLE DE ERRO EM REDES ATM SEM FIO
}

\author{
José Marcos C. Brito e Ivanil S. Bonatti
}

\begin{abstract}
Resumo
As redes ATM (Asynchronous Transfer Mode) foram concebidas considerando a utilização de meios de transmissão ópticos, que apresentam taxa de erro de bit pequena. Um dos principais problemas de se utilizar o ATM em redes sem fio está relacionado à taxa de erro, que é variável e pode assumir valores elevados. Para contornar este problema, mecanismos adicionais de controle de erro devem ser incluídos no enlace ATM sem fio. Os esquemas tradicionais de controle de erro são a correção por retransmissão (ARQ - Automatic Repeat Request) e a correção automática no receptor do enlace sem fio (FEC Forward Error Correction). O uso de FEC ou ARQ no enlace sem fio da rede ATM resulta na diminuição da taxa de erro de bit residual (taxa de erro de bit após a aplicação do mecanismo de controle de erro), no aumento do atraso para transmissão dos pacotes de informação e na diminuição da vazão, devido ao overhead dos mecanismos de controle de erro. Neste artigo, compara-se, analiticamente, o FEC e o ARQ no ambiente das redes ATM sem fio considerando sistemas adaptativos e nãoadaptativos e aplicações em tempo real e não tempo real. Os critérios de comparação utilizados são: o tempo para se transmitir uma PDU (Protocol Data Unit), para aplicações de comunicação de dados não tempo real, e, para aplicações em tempo real, a vazão e os tempos médio e máximo para se transferir uma célula.
\end{abstract}

Palavras-chave: Controle de erro, ATM, redes sem fio, FEC, ARQ.

Abstract
ATM networks have been designed considering the use of
optical links in the physical layer, which present low bit
error rate. The main problem in implementing wireless
ATM networks is the high and variable bit error rate in the
radio link. To overcome this problem, it is necessary to use
an additional error control mechanism in the wireless link.
The traditional techniques for error control are ARQ
(Automatic Repeat Request) and FEC (Forward Error
Correction). Using FEC or ARQ techniques in the wireless
link decreases the residual bit error rate, increases the delay
in transmitting a packet and decreases the throughput, due
to overhead of the error control mechanisms. This paper
presents a comparison of the performances of ARQ and
FEC techniques in wireless ATM networks considering
adaptive and non-adaptive systems and real-time and non-
real-time applications. The criteria to compare the
performances are: the delay to transmit a PDU (Protocol
Data Unit), for real-time applications, and, for non-real-

José Marcos Câmara Brito é do Instituto Nacional de Telecomunicações - Inatel. Ivanil Sebastião Bonatti é da Faculdade de Engenharia Elétrica e de Computação da Universidade Estadual de Campinas - FEEC/Unicamp. E-mails: brito@inatel.br, ivanil@dt.fee.unicamp.br. time applications, the throughput and the average and maximum cell transference delays.

Keywords: Error control, ATM. wireless networks, FEC, ARQ.

\section{INTRODUÇÃO}

Em geral, pode-se dizer que o objetivo de uma rede ATM sem fio é estender as características das redes ATM tradicionais, de forma transparente, por meio de um enlace sem fio, para terminais fixos ou móveis. Ou seja, as redes ATM sem fio devem ter capacidade de integrar diversos tipos de tráfego com qualidade de serviço garantida. Os principais problemas a serem resolvidos para viabilizar as redes ATM sem fio estão relacionados às seguintes áreas de pesquisa [1]-[3]: gerenciamento de mobilidade (incluindo gerenciamento de localização, gerenciamento de conexão, roteamento e handoff), protocolo de múltiplo acesso e controle de erro no enlace sem fio.

Um dos principais problemas para a implementação das redes ATM sem fio é o comportamento do rádio-enlace no que diz respeito à taxa de erro de bit. Uma taxa de erro de bit elevada resulta em valores inaceitáveis para os parâmetros de Qualidade de Serviço (QoS) CER (Cell Error Ratio) e CLR (Cell Loss Ratio), tornando necessária a utilização de mecanismos adicionais de controle de erro. $O$ uso destes mecanismos, por sua vez, reduz a vazão no enlace sem fio e aumenta o tempo necessário para transmitir uma célula, afetando o parâmetro CTD (Cell Tranfer Delay) e, possivelmente, o parâmetro CDV (Cell Delay Variation).

Os esquemas tradicionais de controle de erro são a correção por retransmissão (ARQ - Automatic Repeat Request) e a correção automática no receptor do enlace sem fio (FEC - Forward Error Correction). Na forma tradicional de implementação, o código a ser utilizado, na solução FEC ou ARQ, é fixado de modo a se alcançar os parâmetros de QoS desejados, considerando a maior taxa de erro de bit no enlace. Esta solução é denominada de sistema não-adaptativo e, embora simples, não leva em conta que a taxa de erro de bit no canal é variável e, portanto, não otimiza a utilizaçāo da capacidade do enlace sem fio. Esquemas adaptativos, nos quais o código é escolhido de acordo com a taxa de erro de bit no canal, melhoram o desempenho do sistema, mas são de maior complexidade de implementação, uma vez que é necessário obter uma estimativa da taxa de erro no canal para se definir o código e ter codificadores/decodificadores capazes de implementar códigos com diferentes taxas.

As diversas soluções propostas na literatura para controle de erro em redes ATM sem fio incluem: utilização apenas de ARQ, limitando o número de retransmissões para aplicações sensíveis a atraso [4]: utilização de FEC (podendo utilizar códigos concatenados), associado ou não à utilização de ARQ para a retransmissão de pacotes que ainda contenham erro após a decodificação FEC [5]-[12]: 
utilização de FEC, com um código para proteger o cabeçalho e outro para proteger o pavload [13][14]: utilização de FEC adaptativo, associado ou não à utilização de ARQ [13][15]-[18] e utilização de FEC com maior capacidade que o especificado para o HEC (Header Error Control), adaptativo ou não, para proteger o cabeçalho [19].

Os protocolos ARQ mais utilizados são o Go-Back-N (GBN-ARQ) [4][8] e o Selective Repeat (SR-ARQ) [5][6][8] (ou alguma variante), enquanto os códigos FEC mais utilizados são o $\mathrm{BCH}$ (Bose, Chaudhuri and Hocquenghem) [5][8][10][13]-[15][19] e o Reed-Solomon [7][8][11]-[13][17]. Nas soluções com códigos concatenados, a combinação mais comum é a utilização de um código Reed-Solomon ou $\mathrm{BCH}$ associado a um código convolucional [10]-[11].

Neste artigo compara-se, analiticamente, o FEC e o ARQ no ambiente das redes ATM sem fio considerando sistemas adaptativos e não-adaptativos e aplicações em tempo real e não tempo real. Os critérios de comparação utilizados são: o tempo para se transmitir uma PDU (Protocol Data Unit) composta de $Z$ células ATM, para aplicações de comunicação de dados não tempo real, e, para aplicaçôes em tempo real, a vazão e os tempos médio e máximo para se transferir uma célula.

Na seção 2 apresenta-se o cenário de referência utilizado no artigo, na seção 3 apresenta-se o critério utilizado para a escolha dos códigos nas técnicas ARQ e FEC, na seção 4 compara-se as técnicas de correção de erro utilizando FEC e ARQ para aplicações não tempo real, na seção 5 comparase FEC e ARQ para aplicações em tempo real, as conclusões são apresentadas na última seção.

\section{CENÁRIO DE REFERÊNCIA}

O sistema de referência é composto de um enlace sem fio e $L$ enlaces ópticos. No enlace sem fio, uma estação radiobase é compartilhada por vários terminais, em um esquema de múltiplo acesso. $\mathrm{O}$ mecanismo de controle de erro no enlace sem fio e o múltiplo acesso são implementados em uma camada de enlace, geralmente dividida em uma sub-camada de controle do enlace e uma sub-camada de acesso ao meio, posicionada entre a camada ATM e a camada física.

A técnica de múltiplo acesso dominante nos projetos de redes ATM sem fio relatados na literatura é do tipo TDMA/TDD (Time Division Multiple Access / Time Division Duplex) [4][5][8][15]. Neste artigo considera-se um esquema TDMA/TDD com alocação por demanda, no qual o tempo é dividido em quadros, que são subdivididos em dois periodos denominados de uplink e downlink. No periodo de downlink a estação radiobase transmite para os terminais utilizando multiplexagem por divisão de tempo. $O$ período de uplink é dividido em um período de reserva e um período de transmissão. Os terminais transmitem requisições no período de reserva, utilizando alguma técnica de múltiplo acesso aleatório (como por exemplo o Reservation Aloha), e, quando autorizados pela radiobase, transmitem seus dados no período de transmissão, utilizando TDMA. As janelas de tempo do período de transmissão comportam a transmissão de $N$ células ATM e o overhead da camada de enlace. A Figura 1 ilustra um quadro no enlace sem fio e suas subdivisões.

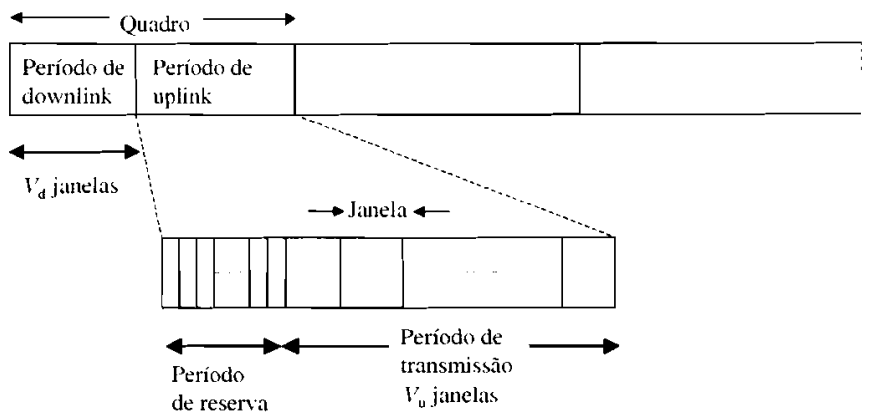

Figura 1. Estrutura do quadro no enlace sem fio.

Considerando as janelas de tamanho fixo e admitindo que as janelas do período de downlink são de mesmo tamanho das janelas de transmissão do período de uplink e que as janelas do período de reserva podem ser representadas como um percentual do tamanho das janelas do período de transmissão, o tempo de quadro pode ser calculado por

$$
T_{q}=\frac{V_{u} \cdot \tau+V_{d} \cdot \tau+\alpha \cdot V_{u} \cdot \tau}{R_{s}}=\frac{V \cdot \tau}{R_{s}}
$$

em que $V_{l}$ e $V_{d}$ representam o número de janelas nos períodos de uplink e downlink, respectivamente, $\alpha$ representa o tamanho do período de reserva, como um percentual do período de transmissão no uplink, $R_{\mathrm{s}}$ é a taxa de transmissão no enlace sem fio, $\tau$ é o número total de bits na janela de transmissão do uplink, que depende da técnica de controle de erro utilizada no enlace sem fio, e $V=V_{u}+$ $V_{d}+\alpha V_{u}$

Nas análises efetuadas nas seções seguintes, parâmetros que afetam as técnicas ARQ e FEC da mesma forma e que podem ser desprezados sem prejuízo para os resultados não foram considerados. Assim, não se considerou:

- os atrasos internos na rede ATM com fio, tais como atrasos de comutação e enfileiramento nos comutadores ATM;

- tempo de propagação na rede;

- tempo necessário para se obter o direito de transmissão no enlace sem fio;

- os overheads da camada de enlace não relacionados diretamente ao processo de codificação para controle de erro.

- tempo gasto no processo de interleaving, embora tenha-se considerado a presença de um interleaving ideal em todas as análises, permitindo admitir que o canal é sem memória e os erros, portanto, não tendam a ocorrer em rajadas.

\section{ESCOLHA DOS CÓDIGOS}

Para a escolha dos códigos nas técnicas ARQ e FEC seguiu-se Cain e McGregor [11] e utilizou-se o seguinte critério: a probabilidade do enlace sem fio entregar uma célula correta para o enlace óptico deve ser maior ou igual à probabilidade de um enlace óptico entregar uma célula correta para o próximo enlace óptico. Considerou-se, para 
efeito de definição dos códigos, que a probabilidade de erro de bit no enlace óptico é $p=10^{-8}$.

\subsection{ESCOLHA DO CÓDIGO NA TÉCNICA ARQ}

Em qualquer protocolo da técnica $\mathrm{ARQ}$, as células estão individualmente protegidas por um código de detecção de erro $(n, k)$. Uma célula que chega à estação radiobase, proveniente de um terminal sem fio, pode não conter erros, com probabilidade $P_{c}$, conter erros detectáveis, com probabilidade $P_{c}$, ou conter erros não detectáveis, com probabilidade $P_{u \text { u. }}$ A probabilidade de uma célula sair do enlace sem fio sem conter erros é dada por

$$
\begin{aligned}
P_{c c a} & =P_{c}+P_{c} P_{c}+P_{e}^{2} P_{c}+P_{e}^{3} P_{c}+\cdots= \\
& =P_{c}+P_{c} \cdot \sum_{k=1}^{\infty} P_{c}{ }^{k}=\frac{P_{c}}{1-P_{e}}=\frac{P_{c}}{P_{c}+P_{u e}}
\end{aligned}
$$

O resultado obtido para $P_{\text {ccut }}$ considerando um número máximo $(N)$ finito de retransmissões é praticamente idêntico, para valores de $N$ razoavelmente grandes (por exemplo, $N=10$ para $P_{c}=0.7$ ), ao resultado obtido pela equação (2), na qual considerou-se, por simplicidade, a possibilidade de infinitas retransmissões. A análise para sistemas mais restritivos quanto ao número de retransmissões é feita na seção 3.1.1.

O cabeçalho da célula ATM é protegido por um código (campo HEC - Header Error Control) com capacidade de correção de erros de 1 bit. O HEC pode operar no modo correção ou no modo detecção. Admitindo que a decodificação do HEC ocorre antes da decodificação do código de detecção de erro da camada de enlace, para que a célula não contenha erro os seguintes eventos devem ocorrer: a célula não contém erro no payload; se o HEC está no modo correção, a célula não contém erro no cabeçalho ou contém erros de um bit; se o HEC está no modo detecção, a célula não contém erro no cabeçalho. Logo, a probabilidade da célula não conter erro, após a decodificação do HEC, pode ser calculada por: Prob(não erro no pavload) $\mathrm{x}$ \{[Prob(não erro no cabeçalho) $\mathrm{x}$ Prob(modo detecção) + Prob(modo correção) x [Prob(não erro no cabeçalho) + Prob(erro de I bit no cabeçalho)]\}. Esta probabilidade é calculada pela equação

$$
P_{c}=(1-p)^{n-40} \cdot\left\{\begin{array}{l}
(1-p)^{40} \cdot\left[1-(1-p)^{40}\right]+ \\
+(1-p)^{40} \cdot\left[(1-p)^{40}+40 p \cdot(1-p)^{39}\right]
\end{array}\right\}
$$

ou

$$
P_{c}=(1-p)^{n} \cdot\left[1+40(1-p)^{39} \cdot p\right]
$$

na qual $p$ é a taxa de erro de bit no enlace.

Se a decodificação do HEC não é considerada, $P_{c}$ é dado por

$$
P_{c}=(1-p)^{n}
$$

Pelo critério adotado para definição dos códigos, tem-se $P_{\text {cca }}$ maior ou igual à probabilidade de um enlace óptico entregar uma-célula sem erro para o próximo enlace óptico $\left(P_{c c o}\right)$, resultando em

$$
P_{u e} \leq \frac{P_{c} \cdot\left(1-P_{c c o}\right)}{P_{c c o}}
$$

em que a probabilidade $P_{\text {coo }}$ é dada pela equação (3), $\operatorname{com} p$ igual à probabilidade de erro de bit no enlace óptico.

Conhecido o valor desejado de $P_{u}$, o número mínimo de bits de paridade necessário pode ser determinado utilizando um algoritmo iterativo e o limitante de Korzhik, dado pela expressão [20]

$$
P_{u e} \leq 2^{-(n-k)}\left[1-(1-p)^{n}\right]
$$

A variação do número de bits de paridade com a probabilidade de erro de bit no canal, considerando ou não a decodificação prévia do HEC e $k=424$ bits, é mostrada na Figura 2. Pode-se observar que a decodificação do HEC antes do código de detecção de erro da camada de enlace não tem influência significativa no número de bits de paridade do código de deteç̧ão de erro.

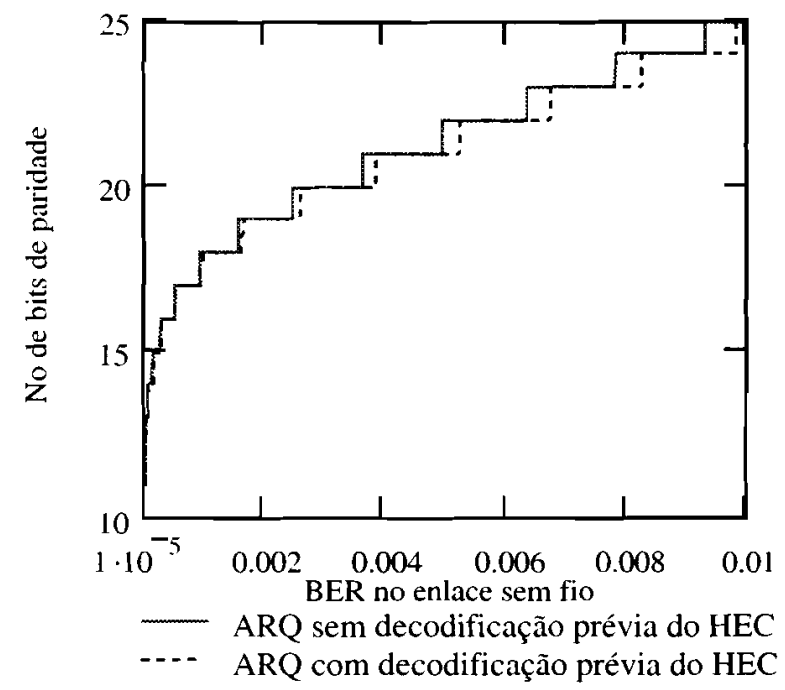

Figura 2. Número de bits de paridade na técnica $A R Q$.

\subsubsection{APLICAÇÕES EM TEMPO REAL}

No caso de se utilizar ARQ no enlace sem fio para aplicações em tempo real, deve haver um limite para o número de retransmissões, de modo que o atraso da célula não se torne excessivo.

Uma célula sai do enlace sem fio contendo erro em duas situações: a célula chega à radiobase contendo erro não detectável, com probabilidade $P_{\text {uc }}$, ou a célula chega à radiobase contendo erro detectável, com probabilidade $P_{c}$, mas o limite de retransmissões, $\rho$, foi alcançado. A probabilidade de uma célula sair do enlace sem fio com erro residual é calculada por 


$$
\begin{aligned}
P_{c c^{\prime}} & =P_{u c}\left(1+P_{c^{\prime}}+P_{e}^{2}+\cdots+P_{e}^{\rho-1}\right)+P_{e}^{\rho}\left(P_{u c}+P_{c}\right) \\
& =\left(P_{u c} \cdot \sum_{j=0}^{\rho} P_{e}^{j}\right)+P^{j}{ }^{\rho+1}
\end{aligned}
$$

A probabilidade $P_{c}$ é determinada por meio da relação $P_{c}$ $+P_{c}+P_{t t^{\prime}}=1$, em que $P_{c}$ é dada pela equação (3) ou (4).

A probabilidade de uma célula deixar o enlace sem fio sem conter erro é dada por

$$
P_{c c a}=1-P_{c e}
$$

A definição do código apropriado é um compromisso entre o número máximo de retransmissões, respeitando o limite imposto pela aplicação, e a redundância do código: à medida em que se aumenta o valor de $\rho$ pode-se diminuir a redundância do código e, à medida em que se diminui o valor de $\rho$, deve-se aumentar a redundância do código.

Analisando o comportamento de $P_{c c a}$ em função de $n$ e $\rho$ verifica-se que existe um valor mínimo de $n$, abaixo do qual

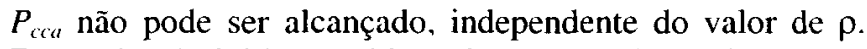
Este valor é obtido considerando que não há limite para o número de retransmissões $(\rho \rightarrow \infty)$. Por exemplo, fixando o valor desejado de $P_{\text {cri }}$ em 0.9999 , o valor mínimo de $n$ é 433, para $p=10^{-4}$.

Da mesma forma, existe um valor mínimo de $\rho$, abaixo do qual $P_{\text {čı }}$ não pode ser alcançado, independente do valor de $n$. Por exemplo, fixando $P_{\text {cca }}=0.9999$, o valor mínimo de $\rho$ é 2, para $p=10^{-4}$.

Um limitante inferior para o número de bits de paridade necessário ao código, para cada valor de probabilidade de erro de bit no enlace sem fio, pode ser determinado por meio do seguinte algoritmo iterativo:

1. Define-se, em função do critério adotado, o valor desejado para $P_{c c a}\left(P_{c c c} \geq P_{c c o}\right)$

2. Fixa-se o valor máximo de $\rho$ imposto pela aplicação, $\rho_{\max }$

3. Encontra-se o valor mínimo de $n, n_{\text {min }}$.

4. Encontra-se o valor mínimo de $\rho, \rho_{m i}$, por meio do seguinte algoritmo:

4.1. Inicializa-se $n_{\text {max }}=2 n_{\text {min }}$

4.2. Inicializa-se $\rho=1$

4.3. Inicializa-se $n=n_{\text {min }}$

4.4. Calcula-se o valor de $P_{u e}$ dado pelo limitante de Korzhik, expresso na equação (6)

4.5. Calcula-se o valor de $P_{\text {cca }}$, utilizando as equações (7) a (9)

4.6. Se o valor calculado no passo 4.5 é maior ou igual ao valor fixado no passo 1 , o valor corrente de $\rho$ é igual ao valor mínimo procurado e o problema está terminado; caso contrário, vá ao passo seguinte.

4.7. Faz-se $n=n+1$

4.8. Se $n \leq n_{\max }$ volte ao passo 4.4 ; caso contrário vá ao passo seguinte

4.9. Faz-se $\rho=\rho+1$ e volta-se ao passo 4.3.

5. Inicializa-se $\rho=\rho_{m i n}$

6. Inicializa-se $n=n_{m i n}$

7. Calcula-se o valor de $P_{u e}$ dado pelo limitante de Korzhik, expresso na equação (6)
8. Calcula-se o valor de $P_{\text {ca } a}$ utilizando as equações (7) a (9)

9. Se o valor calculado no passo 8 é maior ou igual ao valor fixado no passo 1 , os valores correntes de $n \mathrm{e}$ $\rho$ são suficientes para satisfazer o critério fixado, $e$ o código $(n, k)$ pode ser utilizado, fixando o número máximo de retransmissões em $\rho$; caso contrário, faz-se $n=n+1$ e volta-se ao passo 7

10. Faz-se $\rho=\rho+1$.

11. Se $\rho$ é menor ou igual a $\rho_{\max }$ volta-se ao passo 6; caso contrário, o valor de $n$ necessário para cada valor de $\rho$, entre $\rho_{m i n}$ e $\rho_{m a x}$, já foi encontrado.

12. Se houver soluções com mesmo valor de $n$, as que têm maior valor de $p$ são eliminadas.

A Tabela 1 resume os resultados obtidos, para alguns valores de $p$, supondo que o máximo valor de $\rho$ estabelecido pela aplicação é 20 , ou seja, soluções com $\rho$ maior do que 20 não são viáveis. Quando há, para um mesmo valor de $p$, múltiplas soluções possíveis com mesmo valor de $n$ e valores diferentes de $\rho$, apenas a solução com menor valor de $\rho$ foi apresentada na tabela, uma vez que esta solução resulta em melhor desempenho.

\begin{tabular}{|c|c|c|c|c|c|c|c|c|}
\hline \multirow{2}{*}{$p$} & \multirow{2}{*}{$\rho_{\min }$} & \multirow{2}{*}{$n_{\min }$} & \multicolumn{6}{|c|}{ Soluções Possíveis } \\
\cline { 5 - 10 } & & & $\rho$ & $n$ & $\rho$ & $n$ & $\rho$ & $n$ \\
\hline $10^{-6}$ & 1 & 431 & 1 & 431 & --- & --- & --- & -- \\
\hline $5 \times 10^{-6}$ & 2 & 434 & 2 & 434 & --- & --- & --- & -- \\
\hline $10^{-5}$ & 2 & 435 & 2 & 435 & --- & $-\cdots$ & --- & -- \\
\hline $5 \times 10^{-5}$ & 3 & 437 & 3 & 437 & -- & --- & -- & -- \\
\hline $10^{-4}$ & 3 & 438 & 3 & 441 & 4 & 438 & --- & $-\cdots$ \\
\hline $5 \times 10^{-4}$ & 7 & 440 & 7 & 442 & 8 & 441 & 10 & 440 \\
\hline $10^{-3}$ & 12 & 442 & 12 & 442 & --- & $\cdots$ & --- & $\cdots$ \\
\hline $2 \times 10^{-3}$ & 23 & 443 & 23 & 445 & 24 & 444 & 23 & 443 \\
\hline
\end{tabular}

Tabela 1. Códigos ARQ para aplicações em tempo real.

Verifica-se que, para o critério $P_{c c a} \geq P_{c c o}$, não é possível utilizar a técnica ARQ para aplicações em tempo real quando a taxa de erro de bit no canal é muito elevada. As soluções possíveis, em geral, incorporam $n$ igual ao mínimo valor possivel, obtido com $\rho \rightarrow \infty$, e/ou $\rho$ igual ao mínimo valor possível.

\subsection{ESCOLHA DO CÓdIGO NA TÉCNICA FEC}

Na técnica FEC um código de bloco $(n, k)$ é utilizado para corrigir automaticamente erros em pacotes compostos de $N$ células, ou seja $k=424 N$.

Se a capacidade de correção de erros do código é $t$, desconsiderando a influência do HEC, a probabilidade do enlace sem fio entregar o bloco de $N$ células sem erro para o enlace óptico é dada pela distribuição Binomial 


$$
P_{c c f}=\sum_{i=0}^{t}\left(\begin{array}{l}
n \\
i
\end{array}\right) \cdot p^{i} \cdot(1-p)^{n-i}
$$

Como $t$ é, em geral, função de $n-k$, a definição do código que satisfaz a condição imposta só pode ser feita por um processo de busca em códigos conhecidos ou por meio da utilização de limitantes e de um algoritmo iterativo. Neste trabalho optou-se por utilizar o limitante geral de Plotkin, definido pela equação [21]

$$
n-k \geq 2\left(d_{\min }-1\right)-\log _{2} d_{\min }
$$

Se a decodificação prévia do HEC é considerada, o cálculo de $P_{\text {cof }}$ depende do valor de $N$. Por exemplo, para $N$ $=1$, tem-se que a probabilidade do enlace sem fio entregar uma célula sem erro para o enlace óptico é igual à probabilidade de ocorrer até $t$ bits errados em qualquer posição do pacote mais, apenas se o HEC estiver no modo correção, a probabilidade de ocorrer um bit errado no cabeçalho e $t$ bits errados em qualquer posição fora do cabeçalho. A Figura 3 ilustra o número mínimo de bits de paridade necessário ao código, considerando ou não a influência do HEC, considerando $k=424$ bits $(N=1$ célula). Verifica-se, da mesma forma que na seção 3.1 , que a decodificação prévia do HEC não tem influência significativa no número de bits de paridade necessário ao código e, portanto, não será considerada.

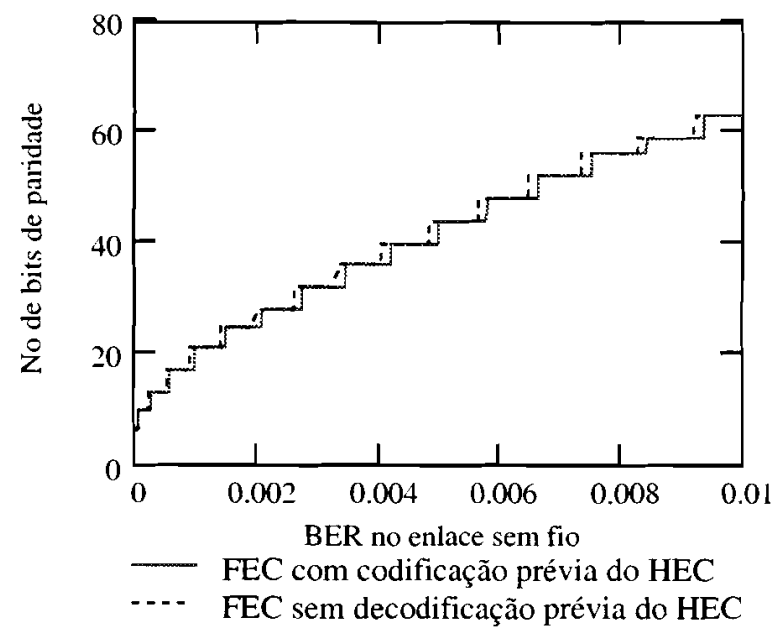

Figura 3. Número de bits de paridade na técnica FEC.

\section{COMPARANDO ARQ E FEC PARA APLICAÇÕES NÃO TEMPO REAL}

$O$ atraso médio fim-a-fim para se transmitir uma PDU composta de $Z$ células é usado como critério de comparação entre o desempenho da técnica ARQ e da técnica FEC para os sistemas com aplicações não tempo real.

\subsection{TEMPO MÉDIO PARA SE TRANSMITIR UMA PDU NO SISTEMA FEC}

No sistema FEC transmite-se um pacote de $N$ células ATM em cada janela de transmissão de cada quadro da estrutura TDMA, com este pacote protegido contra erro por um código $(n, k)$, no qual $k=424 N$.

O número de quadros necessários para se transmitir a PDU é dado pela expressão

$$
Q_{f}=\left\lceil\frac{Z}{N}\right\rceil
$$

na qual o símbolo \lceil\rceil representa o menor inteiro maior ou igual ao argumento.

$\mathrm{O}$ número de células de informação transmitidas no último quadro, $C_{f}$, é dado por $N$, se $Z$ é múltiplo de $N$, ou pelo resto da divisão de $Z$ por $N$, denotado por $\bmod (Z N)$, em caso contrário. Como as janelas de transmissão são de tamanho fixo, o último quadro pode conter células vazias para completar o tamanho da janela de transmissão.

O tempo médio para se transmitir a PDU, desprezando o tempo para transmissão do reconhecimento do terminal de destino para o terminal de origem, é dado pela equação

$$
T_{f e c}=\left[\left(Q_{f}-1\right) T_{q}+\frac{n}{R_{s}}+\frac{424\left(L+C_{f}-1\right)}{R_{o}}+\xi_{f}\right] \gamma
$$

na qual o primeiro termo do colchete representa o tempo referente aos primeiros $\left(Q_{f}-1\right)$ quadros, o segundo termo é o tempo para se transmitir as $N$ células do último quadro (no qual pode haver células vazias) e o terceiro termo é o tempo para se transmitir as células de informação do último quadro na rede com fio. O parâmetro $R_{o}$ é a taxa de transmissão no enlace óptico, o parâmetro $\xi_{\mathrm{f}}$ é o tempo de decodificação do código FEC (desde que este tempo seja menor que o tempo de quadro), o tempo de quadro é dado pela equação (1), com $\tau=n$,o parâmetro $L$ é o número de enlaces na rede óptica e o parâmetro $\gamma$ é o número médio de transmissões necessárias para se receber uma PDU correta, admitindo retransmissão na camada de adaptação. $O$ valor de $\gamma$ é calculado pela equação

$$
\gamma=\sum_{i=1}^{\infty} i \cdot P_{p c} \cdot\left(\mathrm{I}-P_{p c}\right)^{i-1}=\frac{1}{P_{p c}}
$$

na qual $P_{p c}$ é a probabilidade de se receber uma PDU correta, que pode ser calculada, devido ao critério utilizado para escolha do código, por

$$
P_{p c}=P_{c c o}^{(L+1) Z}
$$

\subsection{TEMPO MÉDIO PARA SE TRANSMITIR UMA PDU NO SISTEMA ARQ}

No sistema ARQ transmite-se um pacote de $N$ células em cada janela de transmissão de cada quadro da estrutura TDMA. Como a correção de erro neste sistema se dá por retransmissão, as células do pacote devem estar protegidas individualmente por um código de detecção de erro $(n, k)$, no qual $k$ é igual a 424 mais o número de bits do campo de número de sequiência das células, $\beta$, necessário para a implementação dos protocolos $G$ o-Back-N e Selective 
Repeat. Para o protocolo Stop-and-Wait (SW-ARQ) tem-se $N=1$ e $\beta=0$.

\subsubsection{TEMPO MÉDIO PARA O PROTOCOLO GBN- ARQ}

No protocolo $G o-B a c k-N$ são transmitidas $N$ células a cada janela do quadro TDMA, cada uma protegida por um código de detecção de erro $(n, k)$. Uma célula errada provoca o descarte, e a retransmissão, de todas as células da janela a partir da errada, sendo portanto necessário um campo de número de sequiência das células para que o receptor possa informar ao transmissor o número da célula recebida com erro, resultando em $k=424+\beta$.

$\mathrm{O}$ número de células transmitidas com sucesso em uma janela contendo $N$ células, numeradas de 1 a $N$, desprezando o efeito dos erros não detectáveis, pode ser calculado por

$$
E_{g b}=N \cdot P_{c}{ }^{N}+\left(1-P_{c}\right) \cdot \sum_{i=1}^{N-1} i \cdot P_{c}{ }^{i}
$$

A expressão (15) é exata para janelas contendo $N$ células. No entanto, quando se transmite uma PDU com $Z$ células, utilizando o protocolo GBN-ARQ, a última (ou últimas) janela pode não conter $N$ células de informação, seja porque $Z$ não é múltiplo de $N$, seja porque ocorreu um erro em um quadro qualquer que provocou a retransmissão de células. Assim, o uso da expressão (15) para calcular o número médio de células transmitidas com sucesso a cada quadro, no processo de transmissão de uma PDU com $Z$ células, é aproximado, uma vez que a existência de células vazias no último (ou últimos) quadro não é considerada. Contudo, verifica-se, por meio de simulação de Monte Carlo, que a expressão (15) é uma boa aproximação, se $Z>>$. A Figura 4 ilustra a comparação entre o resultado analítico e o resultado obtido com simulação de Monte Carlo, para $N=5$ e $P_{c}=0.955$, em função de $Z$. [22]

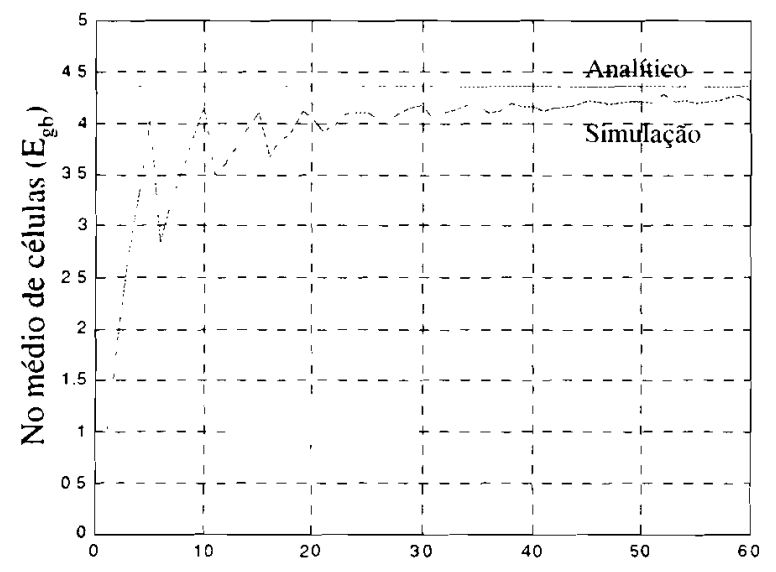

Tamanho da PDU - Z

Figura 4. Número médio de células transmitidas com sucesso, a cada quadro, em função de $Z$ - resultado analítico versus simulação.

O número médio de quadros necessários para transmitir a PDU de $Z$ células é dado por

$$
Q_{g}=\frac{Z}{E_{g b}}
$$

Se todas as células da PDU são transmitidas no enlace sem fio sem erro, o número de células no último quadro TDMA é dado por

$$
C_{c}=\left\{\begin{array}{l}
\mathrm{N} \quad \text { se Z é múltiplo de } \mathrm{N} \\
\bmod \left(\frac{\mathrm{Z}}{\mathrm{N}}\right) \quad \text { caso contrário }
\end{array}\right.
$$

Se ocorreu um erro de transmissão em pelo menos uma das $Z$ células, o número médio de células no último quadro pode ser aproximado pela seguinte expressão heurística

$$
C_{e}=\frac{\sum_{k=1}^{N} k \cdot P_{c}{ }^{k}}{\sum_{k=1}^{N} P_{c}{ }^{k}}=\frac{1-(N+1) \cdot P_{c}^{N}+N \cdot P_{c}{ }^{N+1}}{\left(1-P_{c}\right) \cdot\left(1-P_{c}{ }^{N}\right)}
$$

Usando (17) e (18), o número médio de células no último quadro pode ser calculado por

$$
C=C_{c} \cdot P_{c}^{Z}+C_{c} \cdot\left(1-P_{c}^{Z}\right)
$$

Comparando os resultados obtidos com a expressão (19) com resultados obtidos utilizando simulação de Monte Carlo, verifica-se que a expressão oferece uma aproximação muito boa para o cálculo do número médio de células no último quadro. A Figura 5 apresenta os resultados da comparação, considerando $N=5$ e $P_{c}=0.955$. [22]

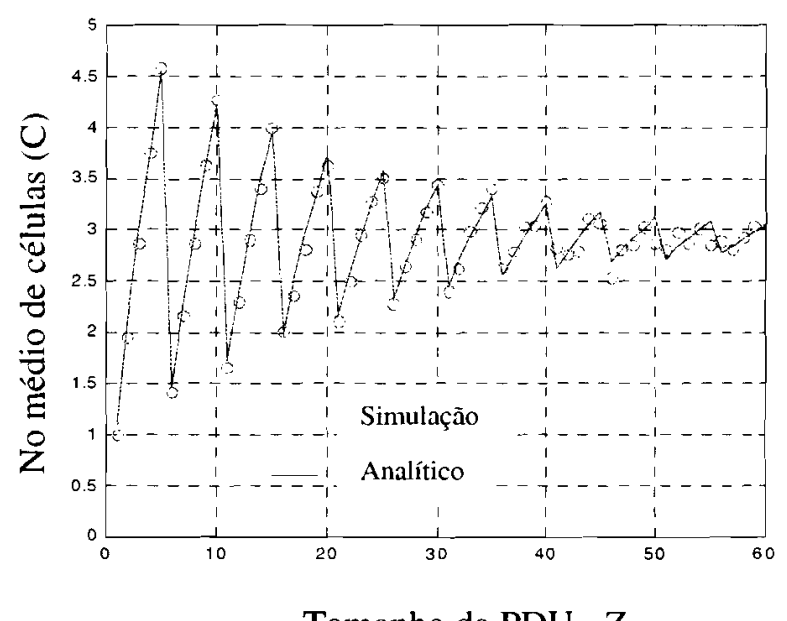

Tamanho da PDU - Z

Figura 5. Número médio de células no último quadro, em função de $Z$ - resultado analítico versus simulação.

O tempo médio para se transmitir a PDU, desprezando o tempo para transmissão do reconhecimento do terminal de destino para o terminal de origem, é calculado pela equação 


$$
T_{g b a}=\left[\left(Q_{g}-1\right) \cdot T_{q}+\frac{C \cdot n}{R_{s}}+\xi_{a}+\frac{424 L}{R_{o}}\right] \cdot \gamma
$$

na qual $\xi_{\text {a }}$ é o tempo de decodificação do código de deteç̧ão de erro, admitindo que este tempo é menor do que o tempo de quadro, $\gamma$ é o número médio de transmissões para que a AAL de destino receba uma PDU correta, admitindo retransmissão na camada de adaptação, que pode ser calculado pelas equações (13) e (14), e $T_{q}$ é o tempo de quadro, calculado pela expressão (1) $\operatorname{com} \tau=N n$.

\subsubsection{TEMPO MÉDIO PARA O PROTOCOLO SW- ARQ}

O protocolo Stop-and-Wait (SW-ARQ) pode ser visto como um caso particular do protocolo GBN-ARQ, $\operatorname{com} N=$ 1. Logo. o tempo médio para se transmitir uma PDU neste protocolo, mantendo as condições definidas para o protocolo GBN-ARQ, pode ser calculado por

$$
T_{s w a}=\left[T_{q} \cdot\left(\frac{Z}{P_{c}}-1\right)+\frac{n}{R_{s}}+\xi_{a}+\frac{424 L}{R_{o}}\right] \cdot \gamma
$$

\subsubsection{TEMPO MÉDIO PARA O PROTOCOLO SR- ARQ}

No protocolo Selective-Repeat são transmitidas $N$ células a cada janela do quadro TDMA, cada uma protegida por um código de detecção de erro $(n, k)$. As células recebidas com erro são descartadas e retransmitidas, sendo portanto necessário um campo de número de sequiência das células para que o receptor possa informar ao transmissor o número da célula recebida com erro, resultando em $k=424+\beta$. Há necessidade de um procedimento de reordenamento das células, que pode ser feito na radiobase ou no terminal de destino. Se o reordenamento for no destino, é necessário utilizar uma camada de adaptação que tenha esta propriedade.

Se não houver erro em nenhuma das $Z$ células, o número de quadros necessários para se transmitir a PDU é dado por $\lceil Z / N\rceil \mathrm{e}$, portanto, o número médio de células transmitidas com sucesso a cada quadro é dado por $Z /\lceil Z N\rceil$. Se houver erro em pelo menos uma das $Z$ células, o número médio de células transmitidas com sucesso a cada quadro pode ser calculado por

$$
E_{c}=\sum_{j=0}^{N} j \cdot\left(\begin{array}{l}
N \\
j
\end{array}\right) \cdot P_{c}^{j} \cdot\left(1-P_{c}\right)^{N-j}=N \cdot P_{c}
$$

Logo, o número médio de células transmitidas com sucesso a cada quadro é dado por

$$
E_{s r}=\frac{Z}{\lceil Z / N\rceil} \cdot P_{c}{ }^{Z}+N \cdot P_{c} \cdot\left(1-P_{c}{ }^{Z}\right)
$$

A expressão (23) não leva em conta a possível presença de células vazias no último (ou últimos) quadro. No entanto, comparando os resultados analíticos com resultados obtidos com simulação de Monte Carlo verificase que a expressão (23) é uma boa aproximação. A Figura 6 mostra a comparação do resultado analítico com o resultado obtido por simulação de Monte Carlo, para $N=5$ e $P_{\mathrm{c}}=$ 0.955. [23]

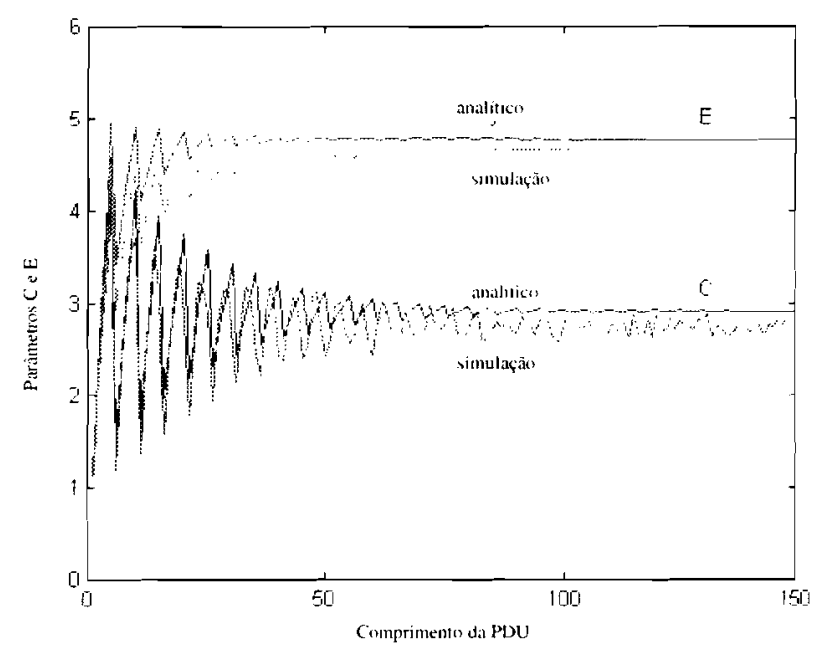

Figura 6. Número médio de células transmitidas com sucesso a cada quadro, $E$, e número médio de células no último quadro, $\mathrm{C}$, em função de $\mathrm{Z}$ - resultados analíticos $\mathrm{x}$ simulação.

O número médio de células no último quadro pode ser calculado pelas equações (17) a (19).

$\mathrm{O}$ número médio de quadros necessários para se transmitir a PDU com $Z$ células é dado por

$$
Q_{s}=\frac{Z}{E_{s r}}
$$

O tempo médio para se transmitir a PDU é calculado pela equação

$$
T_{s r a}=\left[\left(Q_{s}-1\right) T_{q}+\frac{C \cdot n}{R_{s}}+\xi_{a}+\frac{424 L}{R_{o}}+\chi\right] \gamma_{s r}
$$

na qual o tempo de quadro é calculado pela equação (1), $\operatorname{com} \tau=n N$, e $\chi$ é o tempo adicional gasto para se transmitir o número de sequiência das células ATM na rede óptica. admitindo o reordenamento no destino.

Como o número de sequiência é transmitido, na rede óptica, como um overhead adicional dentro dos 48 bytes de payload da célula, ele resulta na transmissão de células adicionais na rede óptica. Devido à estrutura do múltiplo acesso, o número máximo de bytes adicionais a serem transmitidos é igual a $47+N$ vezes o tamanho do campo de seqüência $(\beta)$ e, portanto, o valor máximo de $\chi$ é dado por

$$
\chi_{\max }=\frac{424 \cdot\left\lceil\frac{47+N \cdot \beta}{48}\right\rceil}{R_{o}}
$$


A probabilidade da camada de adaptação de destino receber uma PDU correta diminui ligeiramente com o incremento no número de células transmitidas na rede óptica, e é agora calculada por

$$
\gamma_{s r}=P_{c c o}-\left[(L+1) Z+\frac{\chi \cdot L}{+24}\right]
$$

\subsection{FEC VERSUS ARQ EM SISTEMAS NÃO ADAPTATIVOS}

Como vários parâmetros afetam o desempenho de ambas as técnicas, ARQ e FEC, da mesma forma, pode-se simplificar a comparação definindo um fator de desempenho, $\delta$, como a relação entre o tempo médio para se transmitir uma PDU no sistema FEC e o mesmo tempo no sistema $A R Q$. A técnica $A R Q$ terá melhor desempenho que a técnica FEC quando o fator de desempenho for maior do que um e pior desempenho quando este fator for menor do que um.

Em sistemas não adaptativos, o número de bits de paridade dos códigos deve ser definido considerando a maior taxa de erro de bit no enlace sem fio. Fixando a BER máxima igual a $10^{-2}$ e $\beta=8$ (para os protocolos GBN e SR$A R Q$ ), pode-se determinar, utilizando os resultados apresentados na seção $3, \quad$ o número total de bits (informação mais redundância) dos códigos. A Tabela 2 resume os resultados obtidos, considerando o uso dos limitantes de Korzhik e Plotkin para as técnicas ARQ e FEC, respectivamente. Os resultados são os mesmos, considerando ou não a decodificação prévia do HEC. $\mathrm{O}$ parâmetro $t$ apresentado na tabela é a capacidade de correção de erro do código $\mathrm{FEC}$, em número de bits.

\begin{tabular}{|l|c|c|c|}
\hline & $n$ & $k$ & $t$ \\
\hline Stop-and-Wait ARQ & 449 & 424 & --- \\
\hline Go-Back-N ARQ & 457 & 432 & --- \\
\hline Selective-Repeat ARQ & 457 & 432 & --- \\
\hline FEC, $N=1$ & 487 & 424 & 17 \\
\hline FEC, $N=2$ & 947 & 848 & 26 \\
\hline FEC, $N=5$ & 2302 & 2120 & 47 \\
\hline FEC, $N=10$ & 4545 & 4240 & 78 \\
\hline
\end{tabular}

Tabela 2. Códigos ARQ e FEC determinados a partir dos limitantes de Korzhik e Plotkin.

\subsubsection{FATOR DE DESEMPENHO ENTRE FEC E SW-ARQ}

$O$ fator de desempenho entre a técnica FEC e a técnica SW-ARQ, com uma célula transmitida a cada quadro, é obtido dividindo a equação (12) pela equação (21). Considerando a implementação dos decodificadores em hardware, o tempo de decodificação para ambas as técnicas pode ser desprezado. Admitindo $R_{s}=R_{o}$ e desprezando o tempo de decodificação, o fator de desempenho simplifica para

$$
\delta_{s W}=\frac{V \cdot(Z-1) \cdot n_{f}+n_{f}+424 L}{V \cdot n_{s w} \cdot\left(\frac{Z}{P_{c}}-1\right)+n_{s w}+424 L}
$$

na qual os sub-índices $f$ e sw foram acrescentados em alguns parâmetros para caracterizar se o mesmo está relacionado à técnica $\mathrm{FEC}$ ou $\mathrm{SW}-\mathrm{ARQ}$, respectivamente.

Para qualquer valor de $p$, a taxa de erro de bit no enlace sem fio, a variação de $L$, dentro da faixa usual, praticamente não influencia o resultado para $Z$ grande $(Z>100)$ e tem influência muito pequena para $Z$ pequeno $(Z=10)$. A influência do valor de $V$ no resultado é desprezível para qualquer valor de $Z$.

A Figura 7 mostra a variação do fator de desempenho com a taxa de erro de bit no enlace sem fio, para $Z=5$ e $Z=$ 1000 , assumindo $L=3$ e $V=40$. Percebe-se que o valor de $Z$ praticamente não influencia o resultado. A técnica $A R Q$ tem desempenho pouco melhor que a técnica FEC se a taxa de erro de bit no canal é pequena, $\delta=1.083$ para $p=10^{-6}$, e desempenho muito pior se a taxa de erro de bit é elevada, $\delta$ $=0.014$ para $p=10^{-2}$. As duas técnicas possuem desempenho igual, $\delta=1$, para $p=1.8 \times 10^{-4}$.

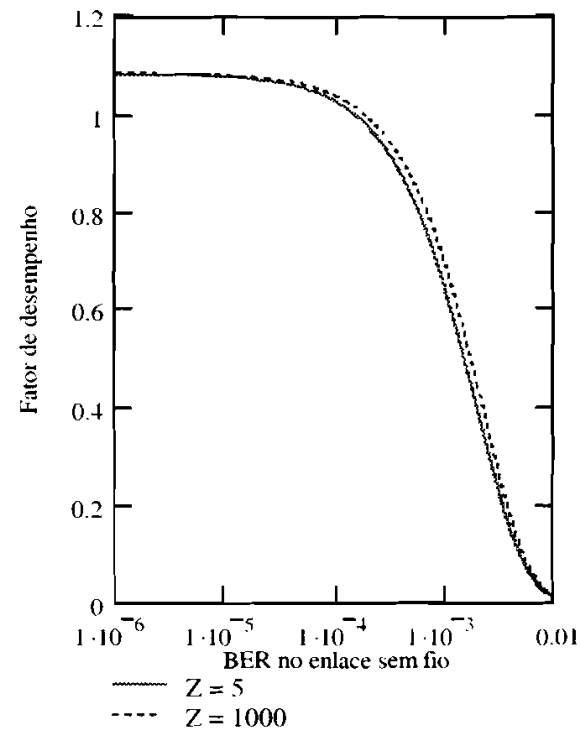

Figura 7. Fator de desempenho entre as técnicas FEC e SW-ARQ.

\subsubsection{FATOR DE DESEMPENHO ENTRE FEC E GBN-ARQ}

$O$ fator de desempenho entre a técnica FEC e a técnica GBN-ARQ, com $N$ células transmitidas a cada quadro, é obtido dividindo a equação (12) pela equação (20). Fazendo $R_{s}=R_{o}$ e desprezando o tempo de decodificação para ambas as técnicas, o fator de desempenho simplifica para

$$
\delta_{g b}=\frac{\left(Q_{f}-1\right) \cdot V \cdot n_{f}+n_{f}+424\left(L+C C_{f}-1\right)}{\left(Q_{g}-1\right) \cdot V \cdot N \cdot n_{g}+C \cdot n_{g}+424 L}
$$


na qual os sub-índices $f$ e $g$ foram acrescentados em alguns parâmetros para caracterizar se o mesmo está relacionado à técnica FEC ou GBN-ARQ, respectivamente.

Os valores de $L$ e $V$ não têm influência significativa no resultado e foram assumidos iguais a 3 e 40 , respectivamente, nesta seção.

A Figura 8 mostra a influência do valor de $Z$ no fator de desempenho, considerando $p=10^{-4}, N=5$ e que $Z$ assume apenas valores múltiplos de $N$. Para $Z>100$, o fator de desempenho é pouco influenciado pelo valor de $Z$.

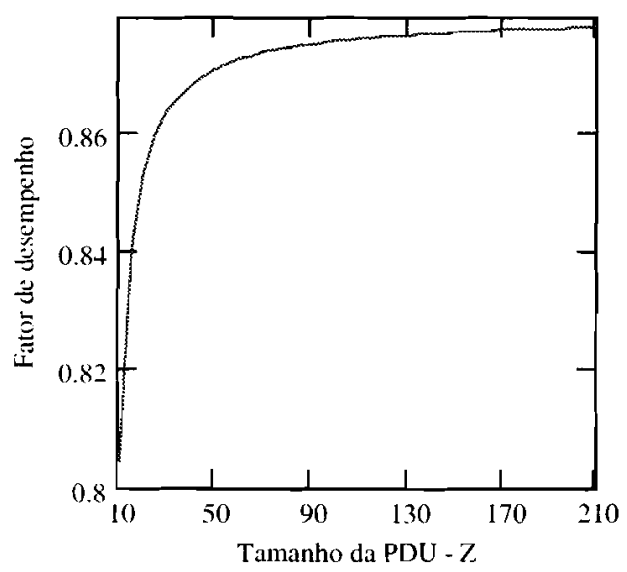

Figura 8. Fator de desempenho entre as técnicas FEC e GBN-ARQ, em função de $Z$, com $Z$ assumindo apenas valores múltiplos de $N$.

A Figura 9 mostra a influência dos valores de $p$ e $N$ no fator de desempenho, fixando $Z=100$. Novamente, a técnica $A R Q$ tem desempenho pouco melhor que a técnica FEC se a taxa de erro de bit no canal é pequena, $\delta=1.036$ para $p=10^{-6}$ e $N=2$, e desempenho muito pior se a taxa de erro de bit é elevada, $\delta=0.005$ para $p=10^{-2}$ e $N=2$. As duas técnicas possuem desempenho igual, $\delta=1, \operatorname{com} N=2$, para $p=5.2 \times 10^{-5}$.

O fator de desempenho decresce com o incremento de $N$, indicando que a técnica FEC é beneficiada quando se transmite mais células ATM em cada janela do quadro.

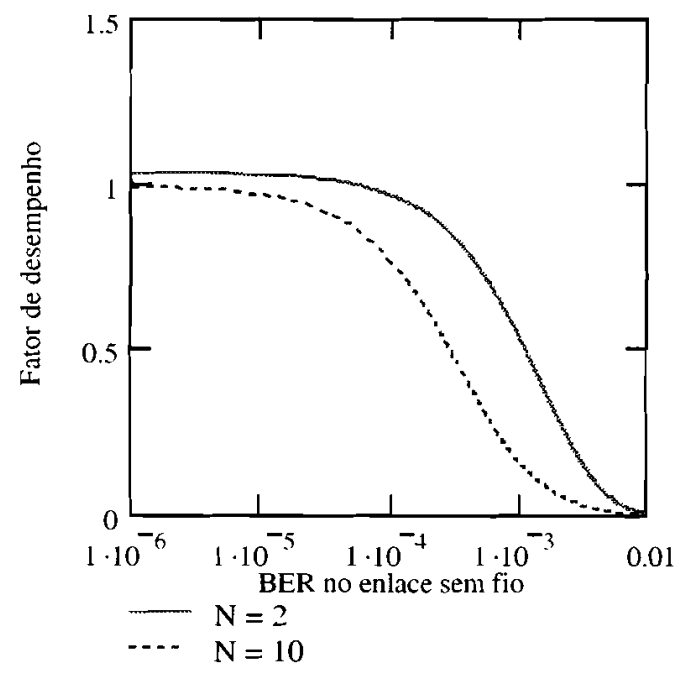

Figura 9. Fator de desempenho entre as técnicas FEC e GBN-ARQ, em função de $p$, para $N=2$ e 10 .
Deve-se observar que, se o número de células em cada janela cresce, $o$ tamanho $n$ do código cresce e a capacidade de correção necessária, $t$, também cresce, tornando a implementação em hardware mais difícil. Se a implementação em hardware não é possível, o atraso de decodificação, $\xi$, não é desprezível, e os resultados apresentados não são corretos. No entanto, é possível implementar a solução FEC em hardware fazendo a codificação de blocos menores, denominados de sub-blocos.

Seja $S$, um sub-múltiplo de $N$, o número máximo de células que podem ser protegidas em um sub-bloco. $O$ número de sub-blocos em um quadro é $N / S$, mas no último quadro, como as janelas são de tamanho fixo, pode-se ter sub-blocos contendo células vazias. O número de subblocos contendo células de informação no último quadro é dado por

$$
J=\left\{\begin{array}{cc}
\frac{N}{S} & \text { se Zé múltiplo de } \mathrm{N} \\
\left\lceil\frac{\bmod (\mathrm{Z}, \mathrm{N})}{\mathrm{S}}\right\rceil \text { se Z não é múltiplo de } \mathrm{N}
\end{array}\right.
$$

O número de células de informação no último sub-bloco é dado por

$$
C_{S}=\left\{\begin{array}{cc}
S & \text { se Zé múltiplo de } S \\
\bmod (Z, S) & \text { se Z não é múltiplo de } S
\end{array}\right.
$$

O tempo para transmitir uma PDU na técnica FEC tornase

$$
T_{f e c}=\left(Q_{f}-1\right) \cdot V \cdot n_{f} \cdot \frac{N}{S}+J \cdot n_{f}+424\left(L+C_{s}-1\right)
$$

e o fator de desempenho passa a ser calculado por

$$
\delta_{g b}=\frac{\left(Q_{f}-1\right) \cdot V \cdot n_{f} \cdot \frac{N}{S}+J \cdot n_{f}+424\left(L+C_{s}-1\right)}{\left(Q_{g}-1\right) \cdot V \cdot N \cdot n_{g}+C \cdot n_{g}+424 L}
$$

A Figura 10 compara o fator de desempenho, para $N=6$ e $Z=100$, considerando a situação na qual não há limite para implementação por hardware e, portanto, o bloco de 6 células é protegido por um único código e a situação na qual o limite $S=1$ é imposto para implementação por hardware e, portanto, o bloco é dividido em seis sub-blocos que são protegidos individualmente. Percebe-se que há um pequeno aumento no fator de desempenho quando a limitação é imposta, indicando uma ligeira queda de desempenho da técnica FEC, mas as conclusões anteriores permanecem praticamente inalteradas. 


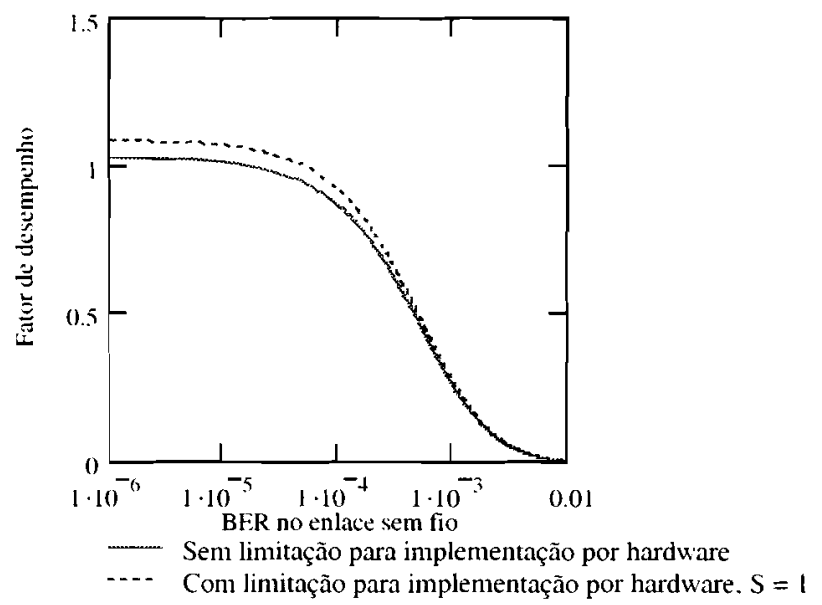

Figura 10. Fator de desempenho entre as técnicas FEC e GBN-ARQ, considerando limitação para implementação por hardware.

\subsubsection{FATOR DE DESEMPENHO ENTRE FEC E SR-ARQ}

$O$ fator de desempenho entre a técnica FEC e a técnica SR-ARQ, com $N$ células transmitidas a cada quadro, é obtido dividindo a equação (12) pela equação (25). Fazendo $R_{s}=R_{o}$ e desprezando o tempo de decodificação para ambas as técnicas, o fator de desempenho simplifica para

$$
\delta_{s r}=\frac{\left(Q_{f}-1\right) \cdot V \cdot n_{f}+n_{f}+424 \cdot\left(L+C C_{f}-1\right)}{\left(Q_{s}-1\right) \cdot V \cdot N \cdot n_{s r}+C \cdot n_{s r}+424 L+\chi} \cdot P_{c c o}{ }^{-L \chi}
$$

em que os sub-índices $f$ e $s r$ foram acrescentados em alguns parâmetros para caracterizar se o mesmo está relacionado à técnica FEC ou SR-ARQ, respectivamente.

Os valores de $L$ e $V$ não têm influência significativa no resultado e são assumidos iguais a 3 e 40, respectivamente, nesta seção. De forma semelhante ao protocolo GBN-ARQ, o fator de desempenho é pouco influenciado pelo valor de $Z$, para $Z>100$.

A Figura 11 mostra a influência dos valores de $p$ e $N$ no fator de desempenho, fixando $Z=100$. Novamente, a técnica ARQ tem desempenho pouco melhor que a técnica FEC se a taxa de erro de bit no canal é pequena, $\delta=1.036$ para $p=10^{-6}$ e $N=2$, e desempenho muito pior se a taxa de erro de bit é elevada, $\delta=0.01$ para $p=10^{-2}$ e $N=2$. As duas técnicas possuem desempenho igual, $\delta=1, \operatorname{com} N=2$, para $p=7.8 \times 10^{-5}$.

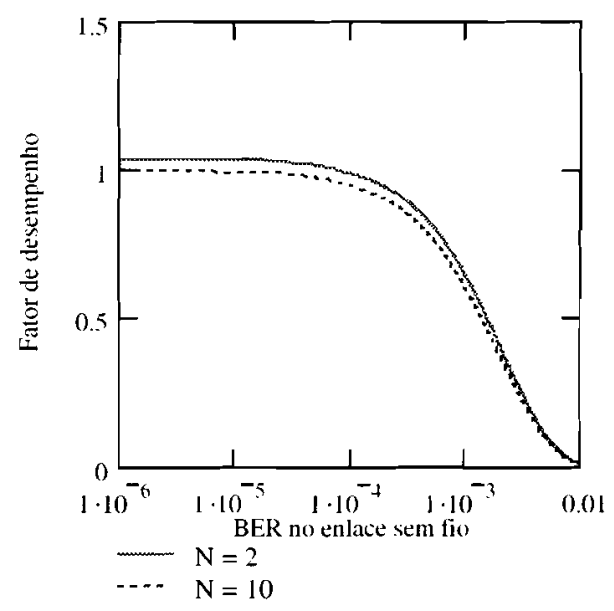

Figura 11. Fator de desempenho, em função da taxa de erro no enlace sem fio.

A Figura 12 mostra a relação entre o tempo necessário para transmitir uma PDU na técnica GBN-ARQ e o mesmo tempo na técnica $S R-A R Q$. A técnica $S R-A R Q$ apresenta ganho de desempenho significativo apenas se a taxa de erro de bit no canal é alta, mas, como mostra a Figura 11, nestas condições a técnica FEC apresenta melhor desempenho. Se a taxa de erro no canal é baixa, situação na qual o $\mathrm{ARQ}$ supera o FEC, o desempenho das técnicas GBN-ARQ e SRARQ é semelhante.

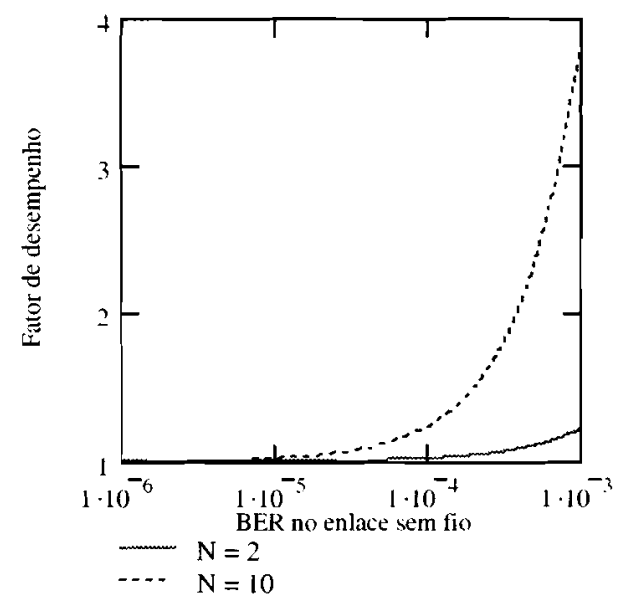

Figura 12. Fator de desempenho entre a técnica GBN-ARQ e SR-ARQ.

\subsection{FEC VERSUS ARQ EM SISTEMAS ADAPTATIVOS}

Nos sistemas adaptativos o terminal sem fio conhece a taxa de erro de bit no enlace e ajusta o código a ser utilizado em função desta taxa. Para efeito de comparação, considerase sistemas adaptativos ideais, nos quais não há overhead para se obter a taxa de erro de bit no canal. Ainda, considera-se que a taxa de erro de bit no canal é constante durante toda a transmissão da PDU e que todas as janelas do quadro estão utilizando o mesmo código, ou seja, todas as janelas são de mesmo tamanho. Com estas hipóteses 
simplificadoras, pode-se utilizar diretamente as expressões para cálculo do tempo médio para se transmitir uma PDU apresentadas na seção 4.2, para cada uma das soluções consideradas, lembrando que $n$ é variável $\operatorname{com} p$.

Utilizando as equações (28), (29) e (34), e determinando o valor de $n$ em função de $p$, pode-se calcular o fator de desempenho entre a técnica FEC e cada um dos três protocolos $A R Q$. Os resultados são apresentados na Figura 13, na qual assume-se $Z=100$ e $N=5$ (para os protocolos GBN-ARQ e SR-ARQ). O fator de desempenho é menor do que um em toda a faixa de probabilidade de erro de bit analisada, indicando que a técnica FEC adaptativa é sempre melhor que as técnicas ARQ adaptativas.

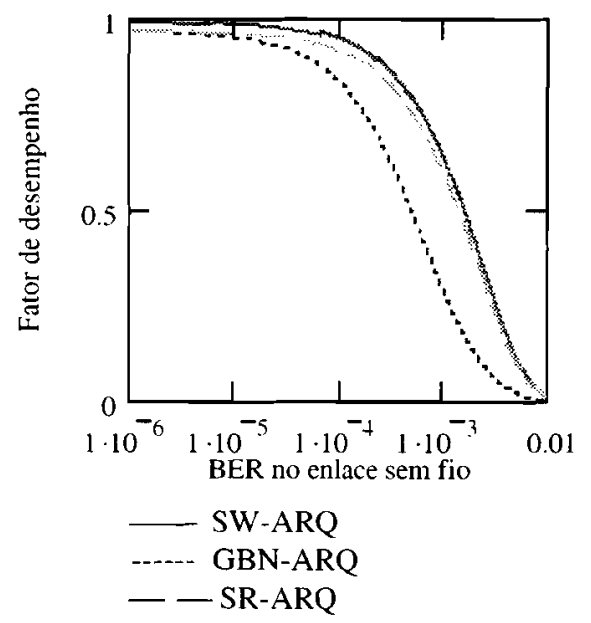

Figura 13. Fator de desempenho entre a técnica FEC e as técnicas $A R Q$, considerando sistema adaptativo ideal.

\section{COMPARANDO ARQ E FEC PARA APLICAÇÕES EM TEMPO REAL}

Nesta seção compara-se, analiticamente, as técnicas FEC e ARQ no ambiente das redes ATM sem fio considerando aplicações em tempo real, nas quais define-se um valor máximo para o atraso que as células podem sofrer (maxCTD, Maximum Cell Transfer Delay) e um valor máximo para a variação deste atraso (max-CDV, Maximum Cell Delay Variation). As comparações são feitas com base nos seguintes parâmetros: vazão no enlace sem fio, taxa de células contendo erro residual (erro após o mecanismo de controle de erro do enlace sem fio) e atrasos médio e máximo de cada célula. Admite-se que uma célula é transmitida em cada janela de transmissão ( $k=424$ bits $)$ e, portanto, o protocolo ARQ é o Stop-and-Wait.

\subsection{ANÁLISE DO SISTEMA ARQ}

$A$ vazão do sistema $A R Q$ é calculada pela equação

$$
\eta_{a}=\frac{k}{n \cdot M}
$$

na qual $M$ é o número médio de transmissões de cada célula no enlace sem fio, sendo dado pela equação

$$
M=\sum_{j=1}^{\rho} j \cdot P_{e^{j}}{ }^{j-1} \cdot\left(P_{c}+P_{u e}\right)+(\rho+1) \cdot P_{c^{\prime}}{ }^{\rho}
$$

na qual $\rho$ é o número máximo de retransmissões, $P_{c}$ é dado pela equação (3) ou (4), $P_{u \in}$ é dado pela equação (5) e $P_{c}=1$ $-P_{c}-P_{u c}$.

$\mathrm{O}$ atraso médio fim-a-fim de uma célula é dado por

$$
\begin{aligned}
& T_{a r t}=\left\{\left(P_{c}+P_{u e}\right) \cdot \sum_{j=1}^{\rho}\left[(j-1) \cdot T_{q}+\frac{n}{R_{s}}\right] \cdot P_{e^{\prime}}{ }^{j-1}\right\} \\
& +\left(\rho \cdot T_{q}+\frac{n}{R_{s}}\right) \cdot P_{e}{ }^{\rho}+\frac{424 L}{R_{o}}
\end{aligned}
$$

em que $T_{q}$ é o tempo de quadro, dado pela equação ( 1 ) com $\tau=n$.

O atraso máximo fim-a-fim de uma célula é dado por

$$
T_{a r t \max }=\rho \cdot T_{q}+\frac{n}{R_{s}}+\frac{424 L}{R_{o}}
$$

\subsection{ANÁLISE DO SISTEMA FEC}

A vazão do sistema FEC é calculada por

$$
\eta_{f}=\frac{k}{n}
$$

O atraso fim-a-fim experimentado por uma célula é constante e calculado por

$$
T_{f r t}=\frac{n}{R_{s}}+\frac{424 L}{R_{o}}
$$

\subsection{COMPARANDO AS TÉCNICAS ARQ E FEC}

A relação entre a vazão da técnica $A R Q$ e a vazão da técnica FEC, denominada de fator de desempenho para vazão, é dada pela equação

$$
\delta_{v}=\frac{\eta_{a}}{\eta_{f}}=\frac{n_{f}}{n_{a} \cdot M}
$$

na qual os sub-índices $a$ e $f$ foram acrescentados para indicar que o parâmetro está relacionado à técnica $\mathrm{ARQ} e$ FEC respectivamente.

O número total de bits para a técnica FEC, $n_{f}$, pode ser encontrado, para cada valor de $p$, utilizando as equações apresentadas na seção 3.2. Este número é o mesmo encontrado para as aplicações não tempo real, uma vez que para o FEC não há diferença de abordagem entre aplicações tempo real e não tempo real.

$\mathrm{O}$ número total de bits para a técnica $\mathrm{ARQ}, n_{a}$, pode ser obtido, para cada valor de $p$, da Tabela 1 na seção 3.1.1. Como mostrou-se nesta seção, a escolha do código, em alguns casos, é um compromisso entre $n$ e $p$, podendo haver 
mais de uma solução que satisfaça o critério de QoS adotado. Neste caso, o código escolhido entre as soluções possíveis é aquele que resulta em melhor desempenho para o critério considerado, vazão ou tempo médio para transmissão de uma célula. Verifica-se que, para todos os valores de $p$ considerados, quando há mais de uma solução possível, a solução que maximiza a vazão e minimiza o atraso é a que apresenta menor $n$ e maior $p$.

A Figura 14 mostra o fator de desempenho para a vazão considerando um sistema adaptativo ideal, no qual o código é escolhido em função da taxa de erro de bit no canal, sem overhead adicional. Observa-se que a técnica FEC tem melhor desempenho em toda faixa de probabilidade de erro considerada.

A Figura 15 mostra o resultado obtido para um sistema não-adaptativo, no qual os códigos foram escolhidos considerando a maior probabilidade de erro que viabiliza a utilização de ambas as técnicas, $10^{-3}$. Verifica-se que a técnica ARQ tem desempenho ligeiramente superior à técnica FEC se a taxa de erro de bit no canal é baixa, $\delta_{1}=$ 1.006 para $p=10^{-6}$, e desempenho inferior se a taxa de erro é alta, $\delta_{1}=0.647$ para $p=10^{-3}$; ambas as técnicas possuem o mesmo desempenho para $p=1.5 \times 10^{-5}$.

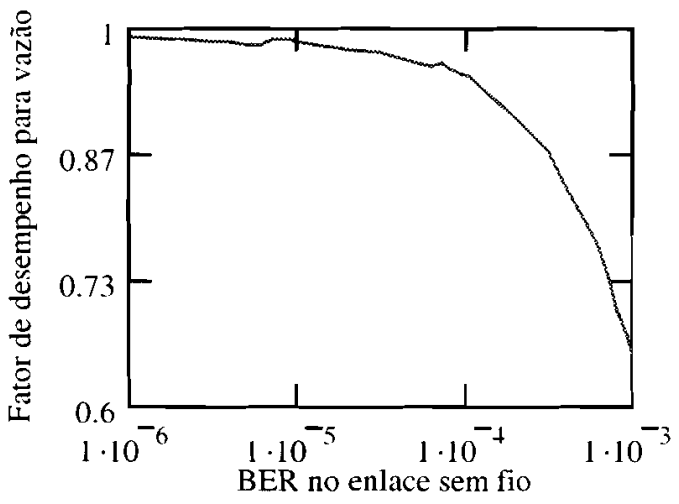

Figura 14. Fator de desempenho para a vazão, para sistema adaptativo.

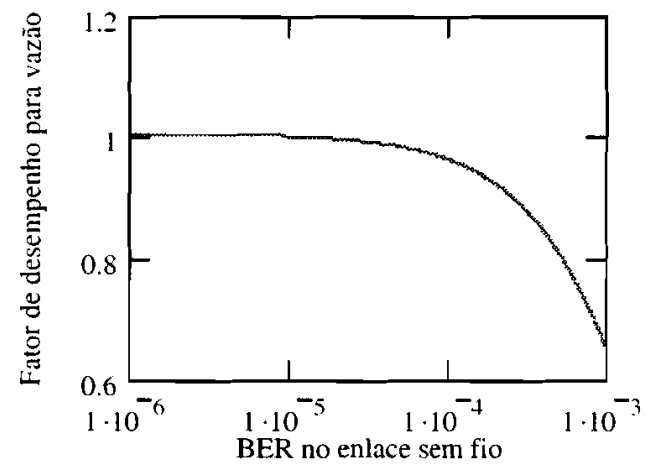

Figura 15. Fator de desempenho para vazão, para sistemas não-adaptativos.

A relação entre o tempo médio para se transmitir uma célula na técnica FEC e o mesmo tempo para a técnica ARQ, denominada de fator de desempenho, é obtida dividindo a expressão (40) pela expressão (37). Considerando $R_{s}=R_{o}$, tem-se

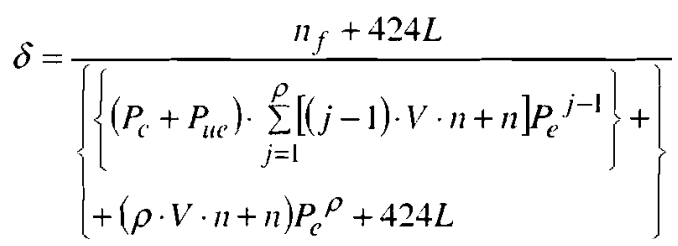

Os resultados obtidos para um sistema não-adaptativo e um sistema adaptativo ideal são mostrados nas Figuras $16 \mathrm{e}$ 17, respectivamente. Em ambos os casos considerou-se $V=$ 40 e $L=3$. Verifica-se que a técnica FEC tem melhor desempenho que a técnica ARQ em ambos os sistemas, em toda a faixa de probabilidade de erro de bit considerada.

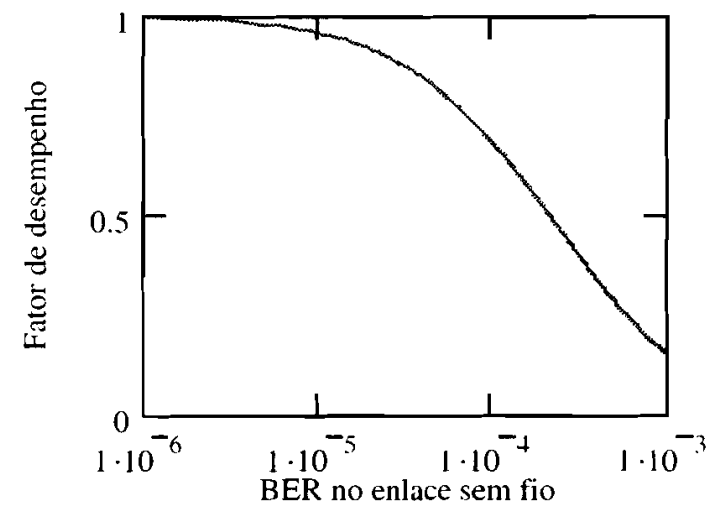

Figura 16. Fator de desempenho para sistemas nãoadaptativos.

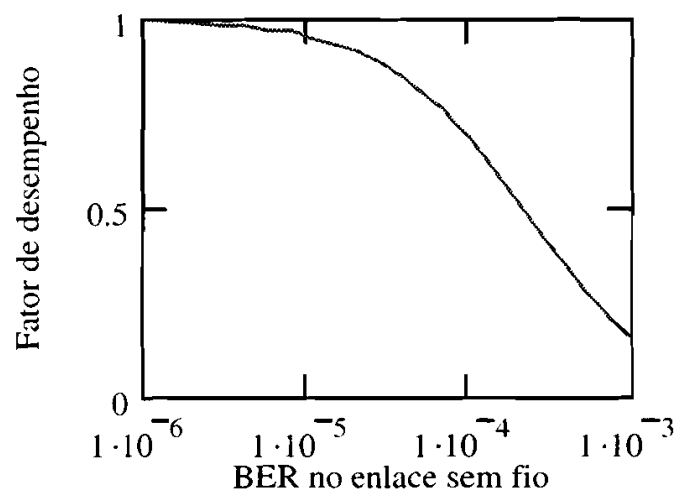

Figura 17. Fator de desempenho para sistemas adaptativos ideais.

\section{CONCLUSÕES}

Neste artigo comparou-se as técnicas ARQ e FEC para controle de erro em redes ATM sem fio. Para aplicações não tempo real o critério utilizado foi o tempo médio necessário para se transmitir uma PDU composta de $Z$ células. Para aplicações em tempo real, os critérios foram: vazão, tempo médio para se transmitir uma célula e tempo máximo para se transmitir uma célula. 
Analisou-se sistemas não-adaptativos, nos quais os códigos são fixados considerando a maior taxa de erro de bit no canal e sistemas adaptativos ideais, nos quais os códigos são escolhidos de acordo com a taxa de erro de bit no canal e nenhum overhead é introduzido para a estimativa da taxa de erro.

A escolha dos códigos, em todas as análises, baseou-se no seguinte critério: a probabilidade do enlace sem fio entregar uma célula correta para o enlace óptico é maior ou igual à probabilidade de um enlace óptico entregar uma célula correta para outro enlace óptico. Este critério garante que as especificações dos parâmetros de QoS da rede ATM sejam atendidas.

Um fator de desempenho, definido como a relação entre o tempo médio para se transmitir uma PDU na técnica FEC e o mesmo tempo para a técnica ARQ foi definido, de modo a facilitar as comparações.

Para sistemas não-adaptativos e aplicações não tempo real, verificou-se que a técnica ARQ possui melhor desempenho que a técnica FEC quando a taxa de erro de bit no canal é baixa e pior desempenho quando a taxa de erro de bit no canal é alta. Verificou-se que o aumento no valor de $N$ beneficia a técnica FEC, quando comparado com as técnicas GBN-ARQ e SR-ARQ.

Para sistemas não-adaptativos e aplicações em tempo real, a técnica FEC sempre possui melhor desempenho quando o critério de comparação é a vazão; quando o critério é o tempo médio para se transferir uma célula, a conclusão é idêntica à do parágrafo anterior.

Para sistemas adaptativos ideais, a técnica FEC possui melhor desempenho em toda faixa de probabilidade de erro de bit considerada.

\section{REFERÊNCIAS BIBLIOGRÁFICAS}

[1] E. Ayanoglu, K. Y. Eng and M. J. Karol, "Wireless ATM: Limits. Challenges, and Proposals" IEEE Personal Communications, pp. 18-33, August, 1996.

[2] A. Acampora, "Wireless ATM: A Perspective on Issues and Prospects", IEEE Personal Communications, pp. 8-17, August, 1996.

[3] D. Raychaudhuri, "Wireless ATM Networks: Architecture, System Design and Prototyping", IEEE Personal Communications, pp. 42-49, August, 1996.

[4] J. Mikkonen, J. Aldis, G. Awater, A. Lunn and D. Hutchison, "The Magic WAND-Functional Overview", IEEE Journal on Selected Areas in Communications, VOL. 16, No. 6, pp. 953972. August, 1998.

[5] D. Raychaudhuri, L. J. French. R. J. Siracusa. S. k. Biswas, R. Yuan, P. Narasimhan and C. A. Johnston, "WATMnet: A Prototype Wireless ATM System for Multimedia Personal Communication", IEEE Journal on Selected Areas in Communications. VOL. 15, No. 1, pp. 83-95. January, 1997.

[6] P. Agrawal et alii, "SWAN: A Mobile Multimedia Wireless Network", IEEE Personal Communications, pp. 18-33, April, 1996.

[7] R. Keller et alii, "Wireless ATM for Broadband Multimedia Wireless Access: The ATMmobil Project", IEEE Personal Communications, pp. 66-80, October, 1999.

[8] J. Mikkonen et alli, "Emerging Wireless Broadband Networks". IEEE Communications Magazine, pp. 112-117, February, 1998

[9] K. Y. Eng et alli, "BAHAMA, A Broadband Ad-Hoc Wireless ATM Local-Area Network", Proc. IEEE International
Conference on Communications (ICC 95), pp. 1216-1223. June, 1995.

[10] F. C. Cheng and J. M. Holtzman, "Wireless Intelligent ATM Network and Protocol Design for Future Personal Communication Systems", IEEE Journal on Selected Areas in Communications, Vol. 15, No 7, pp. 1289-1307, September 1997.

[11] J. B. Cain and D. N. McGregor. "A Recommended Error Control Architecture for ATM Networks with Wireless Links", IEEE Journal on Selected Areas in Communications. Vol. 15, No 1, pp. 16-28, January 1997.

[12] I. Joe, "Error Control for Wireless ATM Networks", PhD Thesis, Georgia Institute of Technology, July, 1998.

[13] C. Schuler, Design and Implementation of an Adaptive Error Control Protocol, GMD Research Series, No21, 1999.

[14] S. Aikawa, Y. Motoyama and M. Umehira, "Error Correction and Error Detection Techniques for Wireless ATM Systems", Wireless Networks, Vol. 3, pp. 285-290, 1997.

[15] J. H. Seo, H. T. Oh and S. W. Seo, "A New MAC and DLC Scheme Considering Channel Conditions in Wireless ATM". Proc. Vehicular Technology Conference (VTC 2000), pp. 987991, Tokyo, Japan, 2000.

[16] K. Yamada, H. Okada and T. H. Lai, "An Integrated Dynamic Error Control Scheme for Wireless ATM Networks", IEICE Transactions on Fundamentals, Vol. E82A. No 7, pp. 1261-1268, July 1999.

[17] I. F. Akyildiz, I, Joe, H. Driver and Y. L. Ho, “An Adaptive FEC Scheme for Data Traffic in Wireless ATM Networks", IEEE Transactions on Networking, Vol. 9. No 4, pp. 419-426. August 2001.

[18] P. R. Denz, "Performance of Error Control Coding Techniques and the Development of a Dynamic Error Control Coding Mechanism for Wireless ATM", PhD Thesis, Faculty of North Carolina State University. 1999.

[19] M. M. Al-Khatib, "New Wireless ATM Automatic Error Control System", PhD Thesis, University of Southwestern Lousiana, 1999.

[20] I. S. Reed and X. Chen, Error-Control Coding for Data Networks, Kluer Academic Publishers, 1999.

[21] J. G. Proakis, Digital Communications, second edition. McGraw-Hill, 1989.

[22] J. M. C. Brito and I. S. Bonatti, "A Comparison of End-toEnd Delay in Wireless ATM Networks using FEC and GoBack-N ARQ in the Wireless Link", Proc. 5th IEEE Malaysia International Conference on Communications (MICC 2001), pp. 84-89, Kuala Lumpur, Malaysia, 21-24 October. 2001.

[23] J. M. C. Brito and I. S. Bonatti, "A Comparison of End-toEnd Delay in Wireless ATM Networks using FEC and Selective Repeat ARQ in the Wireless Link", Proc. Third IEEE International Conference on Information. Communications and Signal Processing (ICICS 2001), 5 pages, Singapore, 15-18 October, 2001.

José Marcos C. Brito diplomou-se em engenharia elétrica no Instituto Nacional de Telecomunicações (Inatel) em 1986, e obteve o mestrado e o doutorado em engenharia elétrica na Unicamp em 1998 e 2003, respectivamente. É professor titular do Inatel, tendo

ocupado os cargos de vice-diretor e de pró-diretor de pósgraduação e pesquisa.

Trabalhou como consultor para várias companhias de telecomunicações e publicou vários artigos na área de telecomunicações. É editor da Revista de Telecomunicações do Inatel e membro de comitês de programa de conferências internacionais. Seus interesses de pesquisa incluem redes de telecomunicações, sistemas de múltiplo acesso, modelagem 
e avaliação de desempenho de sistemas de comunicação, redes sem fios e esquemas de controle de erro.

Ivanil S. Bonatti é engenheiro eletricista formado na Unicamp em 1973, onde obteve o mestrado em telecomunicações em 1975. Obteve o doutorado em automática na Université Paul Sabatier (Toulouse - França) em 1981. É professor titular do departamento de Telemática da Faculdade de Engenharia Elétrica e de Computação da Unicamp. É co-autor de um livro didático sobre circuitos lógicos e de vários trabalhos acadêmicos. Seus principais interesses profissionais estão na área de telecomunicações, particularmente em modelagem, simulação e planejamento de sistemas. 